\title{
Mundos alternativos sin voces femeninas: Las Violetas son flores del deseo de Ana Clavel y Lusus naturae de Teresa P. Mira de Echeverría
}

Recibido: 03/09/2018 | Revisado:09/10/2018|Aceptado:06/11/2018 DOI: 10.17230/co-herencia.16.30.5

Luis C. Cano* Icano@utk.edu

Resumen Este artículo examina la contrastiva variedad de direcciones y perspectivas de dos escritoras hispanoamericanas que han implementado, en sus novelas, motivos y visiones del mundo afines con la narrativa distópica. Por un lado, el diseño y la comercialización de muñecas prepúberes, en un ambiente de deseos clandestinos y sociedades secretas, según lo explora la escritora mexicana Ana Clavel en Las Violetas son flores del deseo (2007); por otro, la fútil búsqueda de un ser humano original, en la extrapolación futurista Lusus naturae (2016), de la novelista argentina Teresa P. Mira de Echeverría. El factor que integra estas visiones contradictorias es la conspicua ausencia de voz, agencia o facultad transformadora por parte de personajes femeninos en ambos relatos.

\section{Palabras clave:}

Ustopia, utopía, distopía, ciencia ficción, poshumanismo, literatura mexicana contemporánea, literatura argentina contemporánea

\section{Alternative worlds without female voices: Las Violetas son flores del deseo by Ana Clavel y Lusus naturae by Teresa P. Mira de Echeverría}

\footnotetext{
Abstract This paper explores the contrasting variety of directions and approaches of two Hispanic American writers who have used motifs and worldviews related to dystopian narrative in their novels. On one hand, the design and commercialization of prepubertal dolls, in an environment of clandestine desires and secret societies, as explored by the Mexican writer
}

* Profesor de español y director asociado del Departamento de Lenguas y Literaturas Extranjeras Modernas, University of Tennessee, Knoxville, Estados Unidos. 
Ana Clavel in Las Violetas son flores del deseo (2007). On the other hand, the futile search for an original human being in the futuristic extrapolation Lusus naturae (2016), by Argentine novelist Teresa P. Mira de Echeverría. The factor integrating these disparate views is the conspicuous absence of voice, agency or transformative faculty on the part of female characters in both stories.

\section{Keywords:}

Ustopia, utopia, dystopia, science fiction, posthumanism, contemporary Mexican literature, contemporary Argentine literature.

I suppose that's what happens to ustopian societies when they die: they don't go to Heaven, they become thesis topics

Margaret Atwood

Varios años atrás, Ursula K. LeGuin, uno de los nombres más prestigiosos de la ciencia ficción (CF) estadounidense, comentaba que

La ciencia ficción se designa como una escritura genérica y como tal se excluye del canon literario. Buenos escritores de ciencia ficción, tanto hombres como mujeres, han sido relegados. Como en el caso de las mujeres, tienden a ser convenientemente olvidados. En consecuencia, perdemos muy buenas novelas. La ciencia ficción se considera una escritura de segunda clase. Podríamos llamarlo "la feminización de la ciencia ficción” (citada por Barr, 1992, p. 16). ${ }^{1}$

La descripción previa introduce, con propiedad, dos conceptos concernientes al desarrollo y la consolidación de la CF en Hispanoamérica, ambos relacionados con la doble acepción del término "género" en español. En primera instancia, la errónea percepción de que se trata de una literatura formulaica, ${ }^{2}$ con poco o nada que contribuir en la articulación de cánones artísticos regionales. El reducido número de textos que ha encontrado un nicho en las historias

1 Traducción propia del original: "Science fiction is called a 'genre' and dismissed from the canon of literature. Good science fiction writers, men and women, are pushed aside. Like women, they tend to be conveniently forgotten. And we are losing very good novels by doing that. All science fiction is treated as if it were inherently second-class. You could call it 'the feminization of science fiction"'.

2 El término "formulaico" describe modalidades escriturales como el relato detectivesco o las historias de horror que recurren al uso de convenciones narrativas familiares a los lectores. Por lo general, las narrativas formulaicas se perciben como modelos escriturales que proporcionan relajación, entretenimiento y escapismo. Para mayor ampliación del tema, véase el estudio de John Cawelti (1976). 
literarias de los países hispanoamericanos han sido, por lo regular, escritos por autores de amplio reconocimiento, cuya aleatoria conexión con la modalidad es el resultado de un fugaz interés, comúnmente orientado hacia la exploración del potencial revitalizador de las narrativas populares en la literatura.

El segundo aspecto sobre el que LeGuin pone el foco de atención es el de la afinidad, largamente institucionalizada, entre la situación de la literatura escrita por mujeres y la posición de la CF como escritura en el establecimiento cultural. Muy pocas autoras en el continente hispanohablante han dedicado una parte representativa de su obra a la producción de $\mathrm{CF}^{3}{ }^{3}$ La chilena Elena Aldunate, la argentina Angélica Gorodischer, la cubana Daína Chaviano y, en menor medida, Ana María Shua y Carmen Boullosa de Argentina y México respectivamente, son los nombres más referenciados cuando se trata de escritoras que incorporan la CF como parte de sus proyectos estéticos.

En su estudio crítico In Other Worlds. SF and the Human Imagination, Margaret Atwood propone el empleo del vocablo "ustopía", "un término que yo creé combinando utopía y distopía — la imaginada sociedad perfecta y su opuesto- porque, desde mi punto de vista, cada una contiene una versión latente de la otra" (2011a, p. 66). ${ }^{4} \mathrm{El}$ acercamiento de Atwood, construido desde la observación y el análisis de su propia escritura, cuestiona los parámetros bajo los cuales se clasifican utopía y distopía como conceptos radicalmente antitéticos. A partir del supuesto de que las configuraciones genéricas (escrituralmente hablando) son resultado de las perspectivas asumidas en el acto de recepción, Atwood argumenta que un cambio substancial de punto de vista es suficiente para transformar una visión utópica a una distópica, por cuanto los principios básicos que determinan ambas aproximaciones les permiten coexistir en un mismo texto (2011a, p. 85$)^{5}$

3 La generalización puede hacerse extensiva a todos los escritores, mujeres y hombres, que escriben CF en Hispanoamérica.

4 Traducción propia del original: "[A] word I made up by combining utopia and dystopia — the imagined perfect society and its opposite — because, in my view, each contains a latent version of the other".

5 No es Atwood la única crítica que propone el fluir entre modalidades. Raffaella Baccolini (2004), por ejemplo, también sugiere la coexistencia textual de utopía y distopía. 
Tomando como punto de referencia el concepto de ustopía propuesto por Atwood, se examina en este ensayo la contrastiva variedad de direcciones y perspectivas de dos autoras que han implementado, en sus novelas, motivos y visiones del mundo afines con la narrativa distópica. Por un lado, el diseño y la comercialización de muñecas prepúberes, en un ambiente de deseos clandestinos y sociedades secretas, según lo explora la escritora mexicana Ana Clavel en Las Violetas son flores del deseo (2007); por otro, la fútil búsqueda de un ser humano original en la extrapolación futurista Lusus naturae (2016), de la novelista argentina Teresa P. Mira de Echeverría.

Con un designio orientado a explorar una obsesión individual (Las Violetas) o comunitaria (Lusus), las dos escritoras construyen universos fundados en ilusiones utópicas que cultivan el germen de una amenaza distópica. La perspectiva masculina dominante en Las Violetas articula la idea de satisfacción ilimitada de deseos sexuales, en un ambiente libre de restricciones morales y normativas jurídicas. Lusus, por su parte, aborda la compulsiva búsqueda de una idealizada tradición patriarcal que excluye a la mujer de todas las posibles instancias de relaciones sociales.

El factor con el que se activa la transferencia ustópica en ambos relatos es la conspicua ausencia de voz, agencia o facultad transformadora por parte de personajes femeninos.

\section{Las Violetas son flores del deseo}

[...] there is nothing without foundation Margaret Atwood

En 1949, año en que el uruguayo Felisberto Hernández publicó "Las Hortensias", la CF aún no disfrutaba de una presencia establecida en el imaginario cultural hispanoamericano. ${ }^{6} \mathrm{Si}$ bien, para entonces, ya era posible establecer un corpus representativo, pocas voces críticas se habían aventurado a aproximarse a tales textos como muestras de CF.

6 "Las Hortensias" se publicó por primera vez en diciembre de 1949, en la revista montevideana Escritura. En diciembre de 2013, la editorial El Cuenco de Plata lanzó una adaptación a historieta, con dibujos de Renzo Vayra. 
No extraña, entonces, que relatos como "Muebles el canario", de 1947 (1983b) y "Las Hortensias", de 1949 (1983a), dos textos que definidamente abordan topoi afines a la CF (los efectos de la publicidad forzosamente implantada en los individuos y la substitución de seres humanos con creaciones artificiales, respectivamente), hayan recibido mayor atención por su filiación a las escrituras de lo fantástico que por sus nexos con otros tipos de ficción especulativa. Aún hoy, pocos estudios se acercan a las obras del narrador uruguayo siguiendo pautas analíticas consonantes con esta escritura. De hecho, la incorporación de Hernández y de su obra en la novela de Clavel ha servido para renovar el interés en "Las Hortensias"?

"Las Hortensias" introduce a Horacio, un coleccionista de muñecas, quien se entretiene figurando relatos para los tableaux preparados por sus empleados. Su esposa contribuye a su afición, organizando escenas sorpresivas protagonizadas por Hortensia, una muñeca que Horacio hizo fabricar usándola como modelo. Hortensia se hace una amiga, hermana o hija para María, mientras Horacio la convierte en su amante. Sin evidencia de si se trata de realidad o imaginación, Horacio observa movimientos en las figuras, situación que María aprovecha para ocupar el lugar de las muñecas, empujándolo a la locura. En un ambiguo desenlace, el hombre camina como un autómata "en dirección al ruido de las máquinas" (1983a, p. 233) de una fábrica contigua a su jardín.

Como se mencionó antes, Ana Clavel recupera el relato de Hernández y lo emplea como fundación argumental para Las Violetas son flores del deseo, obra galardonada con el Premio Novela Corta Juan Rulfo 2005 de Radio Francia Internacional. La trama de la novela presenta a Julián Mercader y a su socio Klaus Wagner, quienes fabrican muñecas pubescentes de tamaño natural, en las que el primero transfiere una atracción incestuosa por su hija Violeta. Las muñecas tienen calor y olor corporal, poseen una sofisticada red de capilares y sangran, características que las populariza entre compradores que fantasean con la violación de menores de edad. Cierto día,

7 Con respecto a la intersección de modalidades escriturales, Mira de Echeverría hace referencia a Roger Zelazny, quien "decía que él escribía ciencia ficción y fantasía indiscriminadamente y que las mezclaba, no porque fuesen la misma cosa sino, justamente, porque no lo son” (en Giorno, 2013). 
Julián recibe una remesa del Uruguay con una muñeca que semeja una mujer adulta. La nota, firmada con las iniciales H. H. (Horacio Hernández), indica que es una Hortensia producida en 1949; explica que el Gobierno de su país aprovechó su reclusión en un sanatorio para cerrar su fábrica de muñecas y registra la ilusión de desflorar una de las Violetas.

Después de que Klaus muere asesinado, Julián recibe la visita de H. H., quien confiesa ser Felisberto Hernández, autor y creador de "Las Hortensias". El visitante le advierte de la existencia de la Hermandad de la luz eterna, una sociedad empeñada en erradicar la lujuria en el mundo. Aterrorizado por el peligro que lo amenaza, Julián padece un infarto. En un ambiguo final, la obra insinúa que Violeta, resentida por haber sido substituida por las muñecas, decide seducir a su padre.

En contraste con los acercamientos críticos principalmente centrados en la escritura de lo fantástico en "Las Hortensias", los estudios sobre Las Violetas no expresan mayor interés por la vacilación argumental como muestra de una modalidad artística específica. El siempre osado y a veces ambiguo tratamiento que la novela realiza de temas tan delicados como el incesto, la pedofilia y el abuso sexual ha mostrado ser más impactante que sus posibles nexos con otras escrituras, en especial si estas, como es el caso de la CF, se siguen percibiendo como modelos de entretenimiento escapista. No obstante, como argumentamos en esta sección del estudio, tanto el relato de Hernández como la novela de Clavel comparten atributos que los vinculan a la narrativa de $\mathrm{CF}$, conexiones que trascienden un mero prurito clasificatorio, para pavimentar direcciones analíticas que amplían las posibilidades de evaluación crítica de las sociedades contemporáneas, una de las características de la imaginación ustópica de la que se alimentan.

Empecemos por indicar que, como ha sido constante en Hispanoamérica, el número de autores que han dedicado una parte representativa de su trabajo literario a la CF es relativamente bajo. Hasta bien entrada la segunda mitad del siglo xx, la disposición más común en el proceso de configuración del corpus hispanoamericano de CF fue la de intelectuales de alto reconocimiento, quienes, motivados 
por el potencial renovador de los géneros narrativos populares, incorporaron rasgos de tales escrituras en algunas de sus producciones escriturales. En efecto, desde el momento en que se empezaron a publicar relatos de lo que en la actualidad se distingue como la CF moderna, los textos de mayor reconocimiento provenían de escritores que dejaron su marca como puntos de referencia obligada en el canon oficial de la literatura continental. Roberto Arlt, Jorge Luis Borges, Pedro Castera, Rubén Darío, Juana Manuela Gorriti, Leopoldo Lugones, Amado Nervo, Clemente Palma y Horacio Quiroga, entre los nombres de más amplio reconocimiento, dedicaron una atención pasajera a la modalidad y el resultado fue un grupo de textos que hoy son de obligada referencia en el canon cienciaficcional.

En una línea afín, Felisberto Hernández establece algunos nexos con la CF, aunque la mayor parte de su obra se orienta a una percepción sui generis de un modelo de lo fantástico que resulta del encuentro incongruente entre sistemas causales independientes.

Ana Clavel exhibe una disposición análoga al acercamiento a las modalidades populares, con una firme tendencia a explorar las motivaciones que guían o definen el deseo sexual.

Si bien, en las obras que nos conciernen, Clavel y Hernández se acercan al motivo de la creación de vida artificial, las narraciones no se expanden con detalladas descripciones de los procesos técnicos involucrados en la producción de las muñecas o con reflexiones sobre los peligros de transgredir las leyes naturales. De hecho, las indicaciones de que estas realmente pueden estar vivas no solo son sucintas, sino que, por su mayor parte, están intencionalmente oscurecidas con un tinte de ambigüedad, que mantiene los relatos en un espacio liminal entre fantasía y CF. Tenues, casi imperceptibles movimientos que sorprenden a los protagonistas, reforzados por observaciones que insinúan un elemental grado de autonomía por parte de las creaciones, son parte del sutil tejido informativo que proporcionan las dos obras:

También es cierto que cada vez eran más flexibles y complacientes [...] y no podía cumplirle a cada una [...] A su modo silencioso me lo hacían saber: un descendimiento de parpados inesperado, el movimiento lateral de un rostro como negándose a participar en los rituales y en los juegos (Clavel, 2007, p. 94). 
[...] miró fijamente la muñeca y le pareció tener, como otras veces, la sensación de que ella se movía. No siempre estos movimientos se producían en seguida; ni él los esperaba cuando la muñeca estaba acostada o muerta; pero en esta última se produjeron demasiado pronto; él pensó que esto ocurría por la posición, tan incómoda, de la muñeca; ella se esforzaba demasiado por mirar hacia arriba; hacía movimientos oscilantes, apenas perceptibles; pero en un instante, en que él sacó los ojos de la cara para mirarle las manos, ella bajó la cabeza de una manera bastante pronunciada (Hernández, 1983a, p. 182).

Esta reserva para comprometerse con la parte más "dura" del discurso cienciaficcional es una de las constantes recurrentes en las variantes de la modalidad en el continente hispanoamericano. Más que centrar el foco de atención en los procedimientos y el léxico de las ciencias - dirección más común en las variantes estadounidenses, por ejemplo-, los escritores de la región han optado por explorar las consecuencias que a nivel individual o social se desprenden de la implementación de tales operaciones, así como de las ambiciones demiúrgicas de los protagonistas, predominantemente masculinos, que lideran los proyectos (Cano, 2006, capítulo 1).

La contribución de Las Violetas a la CF hispanoamericana no se reduce a revitalizar el interés en la obra de Hernández o a cimentar una vía de relaciones intertextuales que favorece la consolidación de un canon para la modalidad. Un aspecto importante en la reescritura que Clavel hace de "Las Hortensias" es el de situar el centro de atención en las relaciones de poder fundadas alrededor de las nociones de "sexualidad" y "género", dos construcciones culturales que han experimentado profundas revisiones con la diversificación de la CF en años recientes. En particular, mediante la actualización crítica de la manera en que se representan tales relaciones en "Las Hortensias", Las Violetas pone en narrativa una variación de lo que Edward Said, en su estudio sobre las ficciones narrativas orientalistas, califica como "fantasía masculina de poder", una sexualización cultural que trasciende los propósitos fundamentales de objetivación, posesión y control, para implementar una autoidentificación con estas operaciones por parte del Otro feminizado. Según Said, una estrategia recurrente del discurso poscolonial es la composición de ficciones en las que se perpetúan y legitiman los más comunes estereotipos genéricos. En tales textos, las mujeres se presentan como "[criaturas] de 
una fantasía masculina de poder. Expresan una sexualidad ilimitada, son más o menos estúpidas y, sobre todo, se muestran dispuestas" $\left(1979\right.$, p. 207). ${ }^{8}$ Aunque, en principio, la propuesta de Said se orientó específicamente a develar el procedimiento como componente central de los discursos imperialistas neocoloniales, se ha convertido en un concepto de central importancia en la revisión de producciones culturales bajo la crítica feminista.

Por supuesto, la época y el lugar de publicación y, más importante aún, el hecho de ser una novela escrita por una mujer, implican variaciones significativas con respecto a la configuración de la fantasía de poder que se materializa en el relato de Hernández. La elección de la voz narrativa en Las Violetas refuerza la perspectiva masculina dominante en "Las Hortensias", mediante el uso de un narrador autodiegético, opción que contrasta con la narración en tercera persona por la que opta el uruguayo. ${ }^{9}$ En adición, la novela de Clavel aborda de manera menos ambigua, que el relato de Hernández, el dominio de las desviaciones del deseo sexual. De hecho, desde el primer instante en que el lector se enfrenta a la desafiante cubierta del libro, una fotografía en blanco y negro tomada por el prestigioso fotógrafo mexicano Rogelio Cuéllar, la reacción de perturbación resulta inevitable. La cámara conduce la mirada a las piernas abiertas de una joven de edad indeterminada, tendida sobre un sembrado de hortensias. La exclusión del rostro y la falda escolar recogida en la cintura dirigen sin reservas el centro de atención hacia los órganos sexuales, apenas encubiertos por un pantaloncito de encaje y ofrecidos como una provocación en las diversas acepciones del término..$^{10}$

8 Traducción propia del original: "[creatures] of a male power-fantasy. They express unlimited sexuality, they are more or less stupid, and above all they are willing". Said analiza esta figura como concreción de una fantasía occidental, que sexualiza y feminiza el Oriente con propósitos de posesión y dominación.

9 La elección de la tercera persona por parte de Hernández es particularmente llamativa, por cuanto es una estrategia empleada con muy poca frecuencia en sus relatos. Por lo general, el escritor escribe predominantemente en primera persona.

10 Según explica Clavel en una entrevista para Alberto Aranda, el grupo Sanborns se negó a distribuir la novela debido a lo explícito de la portada. "Hay una cuestión muy delicada que es que Sanborns se está convirtiendo entonces en una especie de papá moral para decir qué es lo que está bien y qué es lo que no, y nos convierte al público en general en una suerte de minusválidos morales y mentales" (citado por Lavery, 2013, p. 163). En "Ana Clavel's Las Violetas son flores del deseo and peritextuality", Jane Lavery (2013) efectúa un cuidadoso análisis de los elementos peritextuales de la novela de Clavel. 
Portada, temática, discurso y referencias extratextuales, todo el conjunto de la novela se dispone como una disección de los modos en que la mirada, el deseo y el control genital construyen imágenes deformadas del cuerpo y la sexualidad femenina. Coherente con esta aproximación, la novela lleva al extremo la presentación bidimensional de los roles femeninos, los cuales se tratan como simples mecanismos argumentales, sin agencia para tomar decisiones, mostrar emociones y determinar sus propios destinos.

Sea que tal postura se interprete como una inversión crítica del feminismo o como posfeminismo en su más escéptica acepción, lo que sí resulta evidente es que Las Violetas narrativiza la transición de la ilusión utópica de una fantasía masculina de poder a un escenario con inflexiones distópicas, en la que los deseos de Julián, Klaus y Hernández se observan a través de un prisma de descomposición moral, en la que el individuo interioriza y despliega la sintomatología del deterioro social.

En esta instancia de la novela, el estado mental en general (state of mind) al que Margaret Atwood alude como uno de los factores de la construcción ustópica (2011b) asume una posición central, por la importancia que se le asigna al rol del individuo en la reproducción de ideologías y pautas de comportamientos latentes, en una cultura que, a la vez que provee los mecanismos que posibilitan su implementación, suministra los engranajes para penalizarlos. Tal contradicción materializa el declive de la ilusión utópica de los personajes masculinos, quienes se esfuerzan por disponer un mundo ideal autónomo, aislado de la referencialidad extratextual, en el que pueden realizar sus fantasías, mientras forcejean con la obligación de mantener sus acciones dentro de límites legales, morales y éticos.

En todo esto, el tratamiento del tiempo en la novela resulta de capital importancia. Uno de los rasgos de la CF es que, en su búsqueda por desfamiliarizar y reestructurar nuestra experiencia del presente, según lo expone Fredric Jameson (1982, p. 151), la CF pone en primer plano una profunda conciencia de la categoría temporal, que trasciende la organización cronológica en el relato. En efecto, la CF sitúa la problemática del vínculo entre tiempos externos (el tiempo del escritor, el del lector y el momento histórico) y tiempos internos 
(inscritos en el relato y constituidos por los tiempos de la historia, del discurso y de la escritura) en el nivel más superficial de la fábula, donde resulta inevitable el procesamiento consciente por parte del receptor.

Las Violetas recurre a varios procedimientos que tienden a suspender la percepción del fluir temporal y que, en consecuencia, deshistorizan la narración, distanciándola del contexto. Entre estos destacan el énfasis en el discurso mitológico, que intenta explicar las pulsiones que motivan la conducta de los individuos (justificación del deseo tantálico como manifestación de un mito cultural); la ruptura con marcadores de localización que le proporcionen historicidad a la narración, y la intertextualidad artística y literaria, con la que el texto constantemente llama la atención sobre su carácter estético. Una vez que la escritura se instituye en punto de referencia, las divergencias entre instancias temporales desaparecen, con lo que no es posible establecer una clara distinción entre presente, pasado y futuro.

La narración atemporal, tras la que se resguarda la fantasía de poder que hemos venido discutiendo, contrasta diametralmente con la dirección más común en las utopías escritas por mujeres, las cuales, como plantea Dunja Mohr, "Difieren significativamente de las utopías masculinas en términos de contenido narrativo. Temáticamente, las utopías feministas cambian el enfoque hacia la realidad femenina y hacia la vida cotidiana" (2005, p. 24). ${ }^{11}$ El énfasis en el presente y en las intersecciones con lo real, característico de las utopías feministas, se substituye en Las Violetas por un enfoque en la representación de la mujer como un constructo social determinado por roles genéricos rígidos y por expectativas masculinas. Como resultado, la obra de Clavel desafía con insolencia los discursos ficcionales que caracterizan a las mujeres como repositorios de los valores morales que sostienen los principios de constitución y continuidad de la sociedad patriarcal. En su lugar, la representación del cuerpo femenino objetivado, deformado, fragmentado y violentado, posicionado en una suerte de vacuum histórico-social, sirve como brutal

11 Traducción propia del original: "significantly differ in terms of narrative content from male utopias. Thematically, feminist utopias shift the focus to female reality and to everyday life". 
recordatorio de las múltiples formas de control, individual e institucional, de las que la mujer es víctima.

\section{Lusus naturae}

[...] how far can humans go in the alteration department before those altered cease to be human? Which of our features are at the core of our being? What a piece of work is man, and now that we ourselves can be the workmen, what pieces of this work shall we chop off?

Margaret Atwood

Teresa P. Mira de Echeverría es parte del muy reducido número de escritoras hispanoamericanas cuya producción narrativa se orienta principalmente a la CF. Este interés excede, además, los límites de la obra literaria. Tanto su blog personal, como sus entrevistas y reflexiones teóricas muestran una visión decididamente comprometida con la modalidad.

Hasta la fecha, la autora argentina ha publicado las novelas Lusus naturae (2016), El tren (2016) y Antumbra, Umbra y Penumbra (2018), además de un extenso número de relatos divulgados en revistas como Strange Horizons, Axxón, Super Sonic, NM, Valinor, Próxima, Revista Digital miNatura, Ficción Científica y Opera galáctica.

El cuento "Memoria", publicado en Terra Nova. Antología de ciencia ficción contemporánea y finalista del Premio Ignotus en 2013, fue reeditado como libro independiente por la editorial estadounidense Upper Rubber Boot Books. Su relato "La Terpsícore”, ganador de la convocatoria "Alucinadas. Antología de relatos de ciencia ficción escritos por mujeres", fue incluido en un número especial de la prestigiosa revista online norteamericana Strange Horizons. ${ }^{12}$

Lusus naturae, ${ }^{13}$ la novela en la que nos concentramos en las siguientes páginas, es una extrapolación, proyectada 40.000 años, en un futuro en el que los seres humanos deben adaptarse a las condiciones de vida en sistemas. Dispersos por la galaxia, ya no quedan pueblos reconocibles como humanos.

12 La información biográfica y bibliográfica procede del blog personal de la autora (Mira de Echeverría, 2018).

13 No confundir con el relato del mismo nombre, incluido en la colección Stone Mattress (2014) de Margaret Atwood. 
Inspirados por una profecía que vaticina un ser humano intergeneracional eterno, el clan Irará, una familia genéricamente neutra, se propone producir el "homo originalis" en un proceso endogámico que excluye la reproducción sexual. En el presente de la narración, Simeón y su hijo Chaske han creado a Mārama, un individuo que no evoca la humanidad en su forma física, pero sí en ciertos rasgos caracterológicos. Sin embargo, encaran un problema: solo familias sexuadas y exógamas pueden reproducirse de forma indefinida. Enfrentados a la disyuntiva de mezclarse o morir, Simeón y Chaske inician la búsqueda de un alienígena que les permita resolver el impedimento. Su recorrido los lleva al planeta R'li, donde rescatan al único sobreviviente de una masacre organizada por otro clan neutro, en busca de consumar la misma profecía. Tore Q'om, el ejecutor de la matanza, implanta su sangre en un niño, anticipando que los Irará lo rescatarán y lo harán renacer en su clan. El pequeño Sarraillarotz y su padre-hermano Chaske engendran una criatura que recibe el nombre de Quimera.

Mientras más se acerca a la compleción del proyecto, Quimera descubre que en su obsesión por recuperar el pasado, los Irará perdieron de vista el real objetivo de la búsqueda de humanidad:

Si puedo darles a los hombres la patencia de que en cada uno de nosotros se esconde el ser humano original, sin importar nuestra cultura, nuestra forma de reproducción, nuestra elección de vida, nuestro modo de pensar, nuestra forma grífica; entonces habré tenido éxito (2016, p. 157).

Al final del relato, con la mediación de una burbuja-nave espacial, Quimera y Mārama se transforman en una crisálida de la que surge Zoé, un hombre puro como los que dieron origen a la humanidad.

El preámbulo de la novela precisa que la expresión "Lusus naturae" describe un "capricho de la naturaleza; [una] criatura deforme o extrañamente marcada; [una] monstruosidad; [un] bicho raro". De empleo común entre los naturalistas del Renacimiento, la frase se usaba para calificar ciertas "excentricidades" de la naturaleza, fenómenos como restos fósiles, caballos de mar, gigantes o cochas marinas, no explicables a nivel natural y que, en consecuencia, no encontraban un lugar en las taxonomías anteriores a Carl von 
Linneo. ${ }^{14}$ La expresión se ha hecho de uso habitual para referirse a modelos extremos de otredad.

A primera vista, las diferencias entre las dos obras que nos conciernen son bastante amplias. En marcado contraste con el sutil acercamiento empleado en Las Violetas, Lusus reivindica, desde su inicio, su afiliación a la CF. Mientras la narración intimista de Clavel se instala en un presente que no difiere esencialmente de la temporalidad extratextual para indagar los oscuros intersticios del deseo sexual, Lusus se abre al espacio exterior, con un proyecto totalizador en el que un tejido de referentes mítico-religiosos se da a la tarea de explorar construcciones de tipo binario (evolucionismo y creacionismo, naturaleza y artificio, ciencia y arte), a la vez que se problematizan nociones como "origen", "individualidad", "género", "sexualidad" y "tiempo". Si a esto le agregamos que, por su carácter de extrapolación futurista, los referentes cognitivos y la terminología se sostienen en una difusa referencialidad, nos hallamos en presencia de una obra exigente en su lectura, que abiertamente proclama su ascendencia cienciaficcional.

Esta posición de las dos obras con respecto a la modalidad de la CF nos permite identificar otro contraste sobre la diferencia de tradiciones escriturales en que se insertan. En su diálogo con "Las Hortensias", Las Violetas reivindica una tradición que se mueve en el espacio ambiguo entre lo fantástico y la CF en la literatura hispanoamericana. Las explícitas conexiones con el relato de Hernández atraen la atención sobre la problemática de la influencia en la construcción canónica de la CF regional. Lusus, en cambio, sigue una vía muy poco transitada en la narrativa hispanoamericana. Como extrapolación futurista que intenta dar cuenta de las particularidades de un universo transhumano, la obra inicia un diálogo con famosos escritores de CF especulativa. Entre otros, Mira de Echeverría alude a su interés por escritores como Frank Herbert, Roger Zelazny, Philip K. Dick, Ursula LeGuin y Philip Farmer, quienes abordan temáticas relacionadas con la antropología filosófica, la filosofía de la religión y el inconsciente estructural (Giorno, 2013).

14 Para un detallado estudio de la evolución y uso del concepto, referirse al artículo de Findlen (1990). 
Un tercer contraste es que Las Violetas sitúa su propuesta en un espacio liminal entre utopía y distopía, tomando como punto de referencia el deseo individual como concreción de comportamientos que constituyen la base del tramado social de relaciones de género. Lusus, por su parte, plantea interrogantes y postula respuestas de tipo ontológico, que se proponen dar cuenta de la humanidad como una estructura: ¿qué o quiénes somos? ¿Hacia dónde vamos? ¿Qué define el nivel de humanidad de un individuo o grupo? ¿Qué posición tiene la ética cuando se trata de recuperar el sentido de lo humano? La consecuencia más significativa de estas dicotomías es que, al contrario de la novela de Clavel, la cual se enfoca en un individuo intentando justificar la ruptura del entramado moral, Lusus complementa las discusiones filosófico-religiosas con mensajes moralizadores basados en la inclusión y la diversidad.

Dos aspectos en los que coinciden ambos relatos es, primero, el constante movimiento de ida y vuelta entre configuraciones utópicas y distópicas y, segundo, la anulación de la mujer como sujeto activo en los universos narrativos. Como se indicaba en la sección previa, Ana Clavel construye un mundo altamente autorreferencial, en el que los personajes masculinos aspiran a satisfacer fantasías de poder apuntaladas en la más extrema objetivación de lo femenino. Un narrador autodiegético y una focalización interna convalidan la fluctuación ustópica con la que la novela cuestiona la responsabilidad personal y su impacto en la degradación estructural de la sociedad.

Por su lado, Lusus parte del supuesto de que el éxodo que impulsa el desarrollo de la humanidad grifo es el resultado de una catástrofe indeterminada en el planeta de origen. Los ajustes a las condiciones de vida en otros mundos es una acción forzada por la necesidad de supervivencia, y uno de sus resultados a nivel ontológico es el sacrificio de los referentes de lo que significa ser humano.

Si bien, en principio, tal adaptación indica una alternativa ideal que permite concebir un futuro utópico en el que, simultáneamente, se conjugan y se protegen humanidad y naturaleza, la idea que se refuerza es que la variedad y la ausencia de uniformidad tampoco generan un ambiente de valores y aspiraciones compartidas, ni mucho menos propician armonía y libertad. En realidad, los pocos planetas habitados que se describen en la novela se caracterizan por 
retraso, desorden, y por una proliferación de alteraciones genéticas que en el marco del dogma religioso ocasionan discriminación y violencia.

La función cardinal de los "místicos", especie de programa purificador del que hacen parte Simeón y Chaske, es la de la perpetuar la humanidad, según la prescribe una Antigua Biblia Astronómica (ABA). Sin embargo, en contravención con el paradigma que dominó las primeras oleadas del éxodo humano al espacio interior _ - "renunciar a su pureza en favor de su diversidad" (2016, p. 19)_, los místicos optan por un sistema de purificación genética que busca reinstaurar una matriz original de tipo biológico.

De hecho, a pesar de la variedad reproductiva a la que con frecuencia alude el relato, lo único que se articula a un orden aceptable para el objetivo de pervivencia como especie son los núcleos familiares endogámicos, en los que destaca la completa desaparición de lo femenino, tanto como personajes individualizados, como en funciones concernientes a los procesos de gestación y crianza. Como es de esperar en un universo tan heterogéneo, los procesos reproductivos se diversifican y en la abrumadora mayoría de las alternativas que se mencionan, la contribución de la mujer resulta superflua.

Las familias neutras, por ejemplo, punto de vista dominante en la narración, se reproducen mediante una mezcla de clonación y de cuidadosamente seleccionados injertos de ADN; en otros casos, censurados por los místicos como aberraciones degenerativas, se ejecutan cruces en los cuales individuos de una expresión sexual definida (neutros, trinos, etc.) son engendrados bajo el código de otra, procedimientos que, a la vez que permiten conservar rastros genéticos del mundo natural en el planeta originario, eliminan por completo la intervención de lo femenino.

Una contradicción fundamental que plantea la construcción del universo narrativo de Lusus es que la ruptura de la estructura binaria para configurar sociedades basadas en la multiplicidad genérica se desarticula a nivel discursivo, por cuanto las relaciones entre individuos se representan con un lenguaje de marcas referenciales estrictamente masculinas. En las 175 páginas que conforman la novela, solo se encuentran siete instancias en que se establece la existencia de mujeres, ninguna de las cuales resulta de particular importancia en 
el desarrollo de las acciones. En general, las exiguas referencias se emplean para enfatizar los alcances de los programas genéticos de las familias neutras, o sirven para justificar juicios concernientes con la condición de la humanidad en el presente de la narración:

[...] entre doscientos mil millones de hombres, mujeres, neutros, bios y trinos, los esperaba su hijo (2016, p. 19).

Cada ciudadano humano, no importaba su forma grífica o su elección de género (bio, trino, hombre, mujer o neutro), ostentaba como marca de fe y meta última, el cumplimiento del máximo mandato humano: la eternización del hombre (2016, p. 41).

Niños, mujeres, hombres, todos [masacrados] por igual (2016, p. 54).

[Quimera es] bello como un neutro, radical como un macho, misterioso como una hembra (2016, p. 131).

[Mārama no es] ni macho ni hembra (2016, p. 140).

[...] hermoso en su extrañeza, imposible de decidir si [Zoé] era neutro, femenino o masculino (2016, p. 171).

¿Un nombre? ¿Al primer ser humano? ¿Y sin poder definir si era él o ella o lo? (2016, p. 172; en todas estas citas, énfasis añadido).

La inclusión de tales generalizaciones acentúa y afirma el punto de vista androcéntrico que permea el relato. La búsqueda del "homo originalis", objetivo último de la familia Irará, se haya circunscrita por la reducción del linaje familiar a individuos que se autoidentifican con lo masculino (abuelo, padre, hijo, hermano), por la institución de líneas genealógicas patrilineales con reminiscencias bíblicas (Irará/Lem/Ndura/Elur-hontz/Simeón/Chaske/ Mārama), y con un doble discurso que exalta la variedad genérica de los conglomerados humanos, pero que restringe las interacciones familiares a consanguinidad entre hombres.

La muestra más extrema de este acercamiento se concreta en los actos de gestación y alumbramiento de Quimera y Zoé, engendrados sin intervención femenina, con procedimientos que evocan los relatos mitológicos de la concepción de Dioniosos (Zeus toma el niño ya concebido por Semele y lo injerta en su muslo) y de Atenea (Zeus devora a Metis para evitar el nacimiento de su hija, quien más tarde surgiría de la cabeza del dios). 
Lo anterior establece unas condiciones de lectura que producen una sensación de incomodidad análoga a la que describíamos en Las Violetas; pero a diferencia de la novela de Clavel, la cual expone modelos de comportamiento culturalmente proscritos, aunque reivindicados textualmente como manifestaciones de tipo estructural imbricadas en los individuos, en Lusus, la perturbación resulta de la ruptura con un sistema binario de género y sexualidad que se contradice al interior del texto con la afirmación de lo masculino como procedimiento regulador y normalizador, lo cual lleva la propuesta a un sistema análogo al que se está problematizando.

Otro aspecto a considerar es que el proyecto escritural de Lusus contribuye a la expansión de los márgenes de la CF hispanoamericana, con la incorporación de nociones como "transhumanismo" y "poshumanismo", un aporte que no solo afirma las relaciones entre utopía y distopía en la generación de posibles escenarios evolutivos para la humanidad, sino que también establece la intersección de tecnología, literatura y filosofía, en un designio de pretensiones predictivas.

Como una concreción del imaginario utópico que comenzó a abrirse paso en el pensamiento intelectual de la segunda mitad del siglo xx, Michael Hauskeller define el transhumanismo como

[...] una visión particular del mundo y de nuestro lugar en él, según la cual nosotros, no como individuos sino como especie, estamos destinados a ser mucho mejores de lo que actualmente somos.

La asunción general es que [...] lo que realmente somos es aquello en lo que podemos transformarnos. Todavía estamos creciendo. El verdadero ser humano aún está por crearse. Y nosotros mismos lo hemos de crear (citado por Cox y Levine, 2016, p. 76)..$^{15}$

En contraste con el optimismo que sustenta el acercamiento transhumanista, el poshumanismo se inclina por un tono más

15 Traducción propia del original: "a particular view of the world and our own place in it, according to which we, not as individuals, but as a species, are destined to become far better than we currently are.

The general assumption is that [...] what we really are is what we can turn ourselves into. We are still growing up. The true human is still to be created. And it is to be created by us". 
apocalíptico en su apreciación del impacto de la tecnología en el futuro del mundo natural y humano. Las disquisiciones poshumanistas se dan a la tarea de resolver inquietudes ontológicas sobre los significados y alcances del concepto de humanidad, en un período de rápidas transformaciones tecnológicas. Pero, a diferencia de la esperanza utópica que distingue al transhumanismo, el poshumanismo se inclina a magnificar las circunstancias que se extrapolan, generando una apreciación más pesimista, que se materializa en una perspectiva distópica.

Aunque, obviamente, las teorizaciones no siguen parámetros homogéneos, uno de los rasgos del poshumanismo, en que la mayoría de los estudios coinciden, es la tendencia a problematizar las limitaciones del pensamiento binario jerárquico y a plantear alternativas a "Las dicotomías entre mente y cuerpo, animal y humano, organismo y máquina, público y privado, naturaleza y cultura, hombres y mujeres, primitivo y civilizado" (Haraway, 1990, p. 205), ${ }^{16}$ parte de la extensa lista de contradicciones en las que se desenvuelve la humanidad grifo.

Adicionalmente, el tratamiento de género y sexualidades poshumanas, según se representa en la novela, propone especulaciones epistemológicas y éticas contrastivas en un constante fluir entre utopía y distopía. Por un lado, la novela imagina nuevos modelos de género e identidad sexual, que resultan de una hibridez natural-tecnológicahumana. El resultado es que se problematizan nociones como "humanidad", "originalidad", "normalidad", principios que tradicionalmente sostienen las nociones de "normatividad" y "jerarquías" (con consecuencias en cuanto a superioridad racial y discriminación cultural). Por otro, la alineación con los principios del dogma religioso establecido por ABA, y la adopción de un discurso y temáticas que excluyen casi en totalidad la presencia y la agencia de lo femenino, completan un círculo en el que pasado, presente y futuro convergen en una ambigua estructura ustópica.

16 Traducción propia del original: "The dichotomies between mind and body, animal and human, organism and machine, public and private, nature and culture, men and women, primitive and civilized". 


\section{Conclusión}

Un interrogante que deja la lectura de Las Violetas y Lusus es el de por qué, en un período en que la CF se ha dado a la tarea de construir universos distópicos donde las mujeres reivindican el rol de héroes (The Hunger Games de Suzanne Collins, 2008, por ejemplo), Ana Clavel ofrece una propuesta en la que se despoja a la mujer de toda agencia, mientras que Mira de Echeverría la remueve casi por completo de su novela.

Si bien las dos aproximaciones parecerían validar los principios en que se sostienen las relaciones de género en sociedades patriarcales, con la apropiación de puntos de vista y perspectivas masculinas, en ambos casos las autoras recurren a estrategias de desfamiliarización textual, que imponen una lectura crítica de parte de los receptores. De acuerdo con Grace Martin, tal acercamiento no es inusual en las escritoras de CF en Latinoamérica:

A pesar de las variaciones de enfoque con respecto al género y las sexualidades poshumanas en los autores latinoamericanos, una tendencia parece consistente: los autores hombres se adhieren a estereotipos de género escritural —aunque no necesariamente de género sexual-, mientras que las mujeres han tratado los tropos de la ciencia ficción y las representaciones de género de una manera más experimental (2015, p. 249). ${ }^{17}$

En Las Violetas, Ana Clavel ejecuta una reificación de lo femenino, en la que lo socialmente establecido en el contexto de las relaciones sexuales se carga de contenidos distópicos centrados en la degradación moral y en las implicaciones a nivel de relaciones genéricas de poder. Para ello, la obra se torna sobre sí misma, con el empleo de estrategias como la reclusión de los individuos, la separación del contexto social, la autorreferencialidad e intertextualidad, con las que las fantasías de poder llevan en sí mismas el germen de su propia destrucción.

17 Traducción propia del original: "Despite all the variations in Latin American authors' approaches to posthuman gender and sexualities, one trend does seem consistent: male authors stuck to genre-though not necessarily gender-stereotypes, while women authors treated both traditionalscience fiction tropes and gender representations in a more experimental manner". 
En Lusus, por su parte, Mira de Echeverría construye un universo aparentemente sólido, que no requiere de la participación de la mujer para la búsqueda idealizada del retorno al origen. Su apertura a espacios, temporalidades y realidades alternativas, que toman en consideración multiplicidad de variantes, se revierte mediante la validación de lo masculino como único punto de vista válido.

Finalmente, el trabajo de las dos escritoras evidencia la intención de eludir las vías más transitadas, optando por proyectos escriturales que ofrecen intrigantes alternativas para el desarrollo de la CF hispanoamericana en el siglo XXI

\section{Referencias}

Atwood, M. (2011a). In Other Worlds. SF and the Human Imagination. New York: Nan A. Talese/Doubleday.

Atwood, M. (2011b, 19 de octubre). Margaret Atwood: The road to Ustopia. The Guardian.

Recuperado de https://www.theguardian.com/books/2011/oct/14/margaret-atwoodroad-to-ustopia.

Atwood, M. (2014). Stone Mattress. Nine Tales. New York: Nan A. Talese, Doubleday.

Baccolini, R. (2004). The persistence of hope in dystopian science fiction. PMLA, 119(3), 518-521.

Barr, M. S. (1992). Feminist Fabulation: Space/Postmodern Fiction. Iowa City: University of Iowa Press.

Cano, L. (2006). Intermitente recurrencia. Buenos Aires: Corregidor.

Cawelti, John G. (1976). Adventure, Mystery, and Romance: Formula Stories as Art and Popular Culture. Chicago: University of Chicago Press.

Clavel, A. (2007). Las Violetas son flores del deseo. México: Alfaguara.

Collins, S. (2008). The Hunger Games. New York: Scholastic Inc.

Cox, D., y Levine, M. (2016). "I am not living next door to no zombie": Posthumans and prejudice. Critical Philosophy of Race, 4(1), 74-94. Dor: 10.5325/critphilrace.4.1.0074

Findlen, P. (1990). Jokes of nature and jokes of knowledge: The playfulness of scientific discourse in early modern Europe. Renaissance Quarterly, 43(2), 292-331.

Giorno, R. (2013). Entrevista a Teresa Pilar Mira de Echeverría. Axxón, (242). Recuperado de http://axxon.com.ar/rev/2013/05/entrevista-a-teresa-pilar-mira-de-echeverria-ricardogiorno/. 
Haraway, D. (1990). A manifesto for cyborgs. Science, technology, and socialist feminism in the 1980s. In L. Nicholson (Ed.), Feminism/Postmodernism (pp. 190-233). New York: Routledge.

Hernández, F. (1983a). Las Hortensias. En Obras completas de Felisberto Hernández. Tomo 2 (pp. 176-233). México: Siglo Veintiuno Editores.

Hernández, F. (1983b) Muebles el canario. En Obras completas de Felisberto Hernández. Tomo 2 (pp. 156-159). México: Siglo Veintiuno Editores.

Jameson, F. (1982). Progress versus Utopia; Or, Can we imagine the future? Science Fiction Studies, 9(2), 147-158.

Lavery, J. (2013). Ana Clavel's Las Violetas son flores del deseo and peritextuality. Hispanic Research Journal, 14(2), 159-174. DOI: 10.1179/1468273712Z.00000000044

Martin, G. (2015). From the love of robots. Posthumanism in Latin American Science Fiction Between 1960-1999. (Doctoral Dissertation), University of Kentucky. Recuperado de https://uknowledge.uky.edu/hisp_etds/21.

Mira de Echeverría, T. (2016). Lusus naturae. Recuperado de http://www.ficcioncientifica. com/pages/lusus_naturae

Mira de Echeverría, T. (2018). Teresa Mira de Echeverría. Cuentos, novelas, ideas... Recuperado de http://teresamira.blogspot.com/p/hola.html

Mohr, D. (2005). Worlds Apart? Dualism and Transgression in Contemporary Female Dystopias. Jefferson, NC: McFarland \& Co.

Said, E. W. (1979). Orientalism. New York: Vintage Books. 